OPEN ACCESS

Edited by:

Cemal Turan,

Iskenderun Technical University,

Turkey

Reviewed by:

Tommaso Russo,

University of Rome Tor Vergata, Italy

Deniz Ayas,

Mersin University, Turkey

${ }^{*}$ Correspondence:

Claudio Vasapollo

c.vasapollo@irbim.cnr.it

Specialty section:

This article was submitted to Marine Fisheries, Aquaculture

and Living Resources,

a section of the journa

Frontiers in Marine Science

Received: 30 April 2019 Accepted: 09 January 2020

Published: 29 January 2020

Citation:

Vasapollo C, Virgili M, Bargione G, Petetta A, De Marco R, Punzo E and

Lucchetti A (2020) Impact on

Macro-Benthic Communities of Hydraulic Dredging for Razor Clam

Ensis minor in the Tyrrhenian Sea.

Front. Mar. Sci. 7:14.

doi: 10.3389/fmars.2020.00014

\section{Impact on Macro-Benthic Communities of Hydraulic Dredging for Razor Clam Ensis minor in the Tyrrhenian Sea}

\author{
Claudio Vasapollo ${ }^{*}$, Massimo Virgili', Giada Bargione ${ }^{1,2}$, Andrea Petetta ${ }^{1,2}$, \\ Rocco De Marco', Elisa Punzo ${ }^{1}$ and Alessandro Lucchetti ${ }^{1}$ \\ ${ }^{1}$ Institute of Biological Resources and Marine Biotechnologies (IRBIM) of Ancona, Italian National Research Council (CNR), \\ Ancona, Italy, ${ }^{2}$ Department of Biological, Geological and Environmental Sciences, University of Bologna, Bologna, Italy
}

Bivalve molluscs fishery is of great importance along the Italian coasts, both in economic and landing terms, and different edible bivalve species are harvested both in Adriatic and Tyrrhenian Seas. A medium-term assessment of the impact of the hydraulic dredges targeting razor clam Ensis minor on macro-benthic community was made during two surveys carried out in winter 2017 and late spring - summer 2018 in central Tyrrhenian Sea, which represents the main fishing ground for this species. The study area was located between 1 and $4 \mathrm{~m}$ depth, within 0.3 nautical miles from the coast. A net sampler (40 cm width, $18 \mathrm{~cm}$ height, and $14 \mathrm{~mm}$ mesh size) was mounted on a commercial dredge ( $3 \mathrm{~m}$ width) and enabled to collect specimens of the smallest sizes for the entire community present in the areas. A control area was identified where fishing does not occur, in order to compare exploited and not exploited sea bottoms. The results show that benthic assemblages found in dredged areas are characterized by species living in high-energy habitat, due to the closeness to the shore, and thus showing a high resilience at medium-term disturbs. Differences in species richness were not clearly evident both for the entire community and for the mollusc assemblages evaluated over the two surveys, among the control and the impacted areas, with few exceptions mainly depending on local conditions and anthropic pressure. Thus, even if the benthic community is typical of a moderately disturbed environment, the effects of fishing on the community structure are still discernible over and above the natural variation.

Keywords: hydraulic clam dredging, fishing impacts, Ensis minor, benthic communities, species diversity

\section{INTRODUCTION}

Fishing disturbance on benthic communities is an important issue of fisheries management (Reiss et al., 2009). Effects appear to vary with fishing gear, habitat, and fishing intensity (Thrush and Dayton, 2002). It is therefore important that, as new fisheries and exploitation methods develop, impact studies are undertaken to aid future management 
decisions. There is now good evidence that commercial fishing has a profound effect on marine ecosystems (Kaiser, 1998; Tuck et al., 2000; Szostek et al., 2015). In the last three to four decades, the problem of the impact of fishing gears on the seafloor has spawned a number of studies that summarize and synthesize the environmental effects of fishing [see Thrush and Dayton (2002) for a review]. The information extrapolated enriched the debate over fisheries management and marine conservation. Disturbance regimes play a fundamental role in influencing biodiversity and generating patchiness (Thrush and Dayton, 2002; Hauton et al., 2003; Morello et al., 2005) and the resultant spatial heterogeneity created by local disturbance events (such as that produced by fishing gears) can increase the presence of opportunistic species in soft-sediment habitats. Although the soft-sediment seafloors are not always seen as highly structured as some marine reef habitats, they actually support extremely high species diversity (Snelgrove, 1999). Soft-sediment communities have a crucial role to many ecosystem processes as well as services that sustain fisheries provisioning food for human consumption. Beside the functional role, benthic organisms are key factors for the sediment stability, water column turbidity, nutrients and carbon cycles, and contaminant sequestering processes (see Thrush and Dayton, 2002). Many fishing gears (trawls and dredges) are dragged over the sea bottom and their physical impact depends on their mass, the degree of contact with the seafloor and the speed of trawling, influencing particle size, resuspensions regimes, and biogeochemical fluxes (Palanques et al., 2001; Lucchetti and Sala, 2012), as well as the microbial activity (Watling et al., 2001). Moreover, the sediment quality is intimately linked to the presence of fisheries target species and to the benthic community supporting it.

Generally, one approach to investigate the impact of fishing gears on benthic invertebrates is to focus on the immediate effects of the passage of the fishing gears over previously undisturbed benthic communities (Morello et al., 2005). An alternative approach comprise the comparison between benthic communities across gradients of fishing effort, focusing on changes over prolonged periods (Frid et al., 1999). Results of the latter approach indicate that persistent disturbance from fishing may alter benthic fauna to more resilient and adapted communities (Kaiser et al., 2000), even hypothesizing an equilibrium disturbed state in which an increase in disturbance has little additional impact (Reiss et al., 2009).

Clams harvesting represents an important fishing activity in the Mediterranean Sea and in the Black Sea, but these fisheries (i.e., dredge fisheries) create a very high share of discards (over $15 \%)$ in almost all the subregions where these activities take place. A large proportion of the discarded catch is mainly composed of undersized commercial individuals and non-commercial specimens of molluscs, decapods, and echinoderms (Urra et al., 2017). Furthermore, a significant proportion of target species caught or left on the dredge path have damaged shells (with chipped margins, holed umbos, broken or smashed valves), which causes indirect shellfish mortality and economic loss (Moschino et al., 2003). In the northern Adriatic Sea, where this kind of fisheries is a common practice, discards are estimated to be $50 \%$ of the total catch, $30 \%$ of which are undersized target species and $20 \%$ are other benthic invertebrates (Morello et al., 2005).
One of the most ecologically and economically important superfamilies of marine bivalves is Solenidea which has two families, Pharidae and Solenidae, referred to as razor clams (Ensis spp. and Solen spp.). In an ecological context, the contribution of razor clams to trophic food webs includes serving as prey to crabs, gastropods, sea birds, and demersal fish. The razor clam fishery is an economically influential industry. Along the European coasts in 2012 more than 33 million Euros have been estimated as the amount of landing value (considering both Ensis spp. and Solen spp.), corresponding to more than 3500 tons of landing (Eurostat, 2018) ${ }^{1}$. After 2012, both landings and gains suddenly decreased oscillating between 5 and 10 million Euros. This could depend on the European Regulation 1967/2006 that imposed a ban on fishing within 0.3 nautical miles (nm) along the European coasts. In most of the countries (Italy comprised) this closure prevented fishers from catching razor clams, that live mainly inside the $0.3 \mathrm{~nm}$. In regions like those of the northern Adriatic Sea, where razor clams, due to the morphology of the bottom (shallow waters remain at higher distances), can live even more distant than $0.3 \mathrm{~nm}$, thus explaining why an amount of gain after the EU regulation remained.

Along the Italian coasts, historically razor clams fishery grounds were mainly located in the northern Adriatic Sea (Veneto and Friuli Venezia Giulia) and along the central Tyrrhenian Sea (Lazio and Campania), although in several areas artisanal collection by hand of these animals has traditionally taken place at less than $1 \mathrm{~m}$ depth. In the last 7 years, the Adriatic razor clams community experienced an exceptional decrease of individuals leading to a collapse of the species Ensis minor with a strong crisis of the fishing sector that turned definitively to other bivalve species (Chamelea gallina and Callista chione). Although it is not clear what caused this clam crisis, most of the attention has been paid to the MOSE (Electromechanical Experimental MOdule) building, a series of mobile dams acting to avoid the flooding of the city of Venice and that radically changed the main current flows and sedimentation (Strozzi et al., 2009; Amos et al., 2010). The works started in 2003 and they are currently completed by $85 \%$.

In the Tyrrhenian Sea the razor clam fishery did not experience the same crisis as in the Adriatic Sea, although the fishery had severe problems linked to the closure of the $0.3 \mathrm{~nm}$ from the coast, that, because of the morphology of the seafloor, corresponds to the main habitat for the razor clam E. minor. In 2017, the Italian Ministry of Agriculture, Food and Forestry asked for and obtained the extension to fish inside the $0.3 \mathrm{~nm}$ from the coast as a 3-year experiment to subsequently ask for an exception to the European Regulation. Since then, a series of annual surveys are being done to assess the status of the resource and of the associated fauna, and to confirm the presence of E. minor inside and not further the $0.3 \mathrm{~nm}$.

In the present work the results about the impact of the razor clam dredgers in the Tyrrhenian Sea are reported with a particular emphasis on the bivalve molluscs assemblages, that are the most representative taxon of the entire benthic community (Petetta et al., 2019).

${ }^{1}$ https://ec.europa.eu/eurostat 


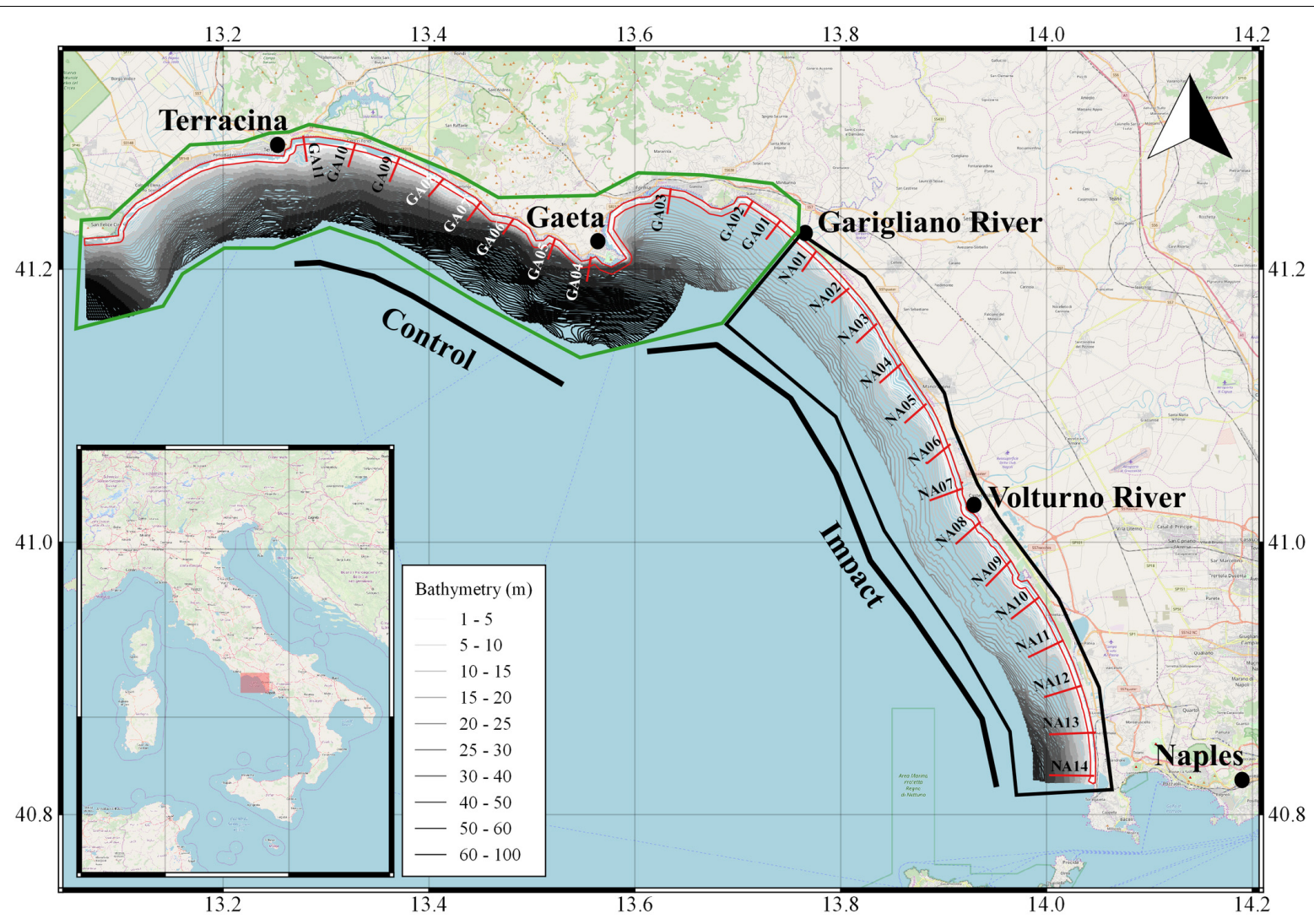

FIGURE 1 | Study area of the dredge.1pc impact surveys. Bars in red represents the transects placed in the two Maritime Compartments of Naples and Gaeta (limited by black and green boxes, respectively). The red polygon represents the $0.3 \mathrm{~nm}$ limit within which the surveys were done and that the European Regulation $1967 / 2006$ closed. The bathymetries between the coastline and $4 \mathrm{~nm}$ are represented as well.

\section{MATERIALS AND METHODS}

\section{Study Area}

The study area is located in central Tyrrhenian Sea and includes two compartments, Naples and Gaeta, that are in continuity and are characterized by low and sandy coasts (Figure 1). The compartment of Naples extends to about $52 \mathrm{~km}$, while the one of Gaeta extends to more than $150 \mathrm{~km}$, but the area where fishing is permitted extends for about $8 \mathrm{~km}$. The compartment of Naples is characterized by the presence of the Volturno river, the main river flowing in the Tyrrhenian Sea, while the main river in the compartment of Gaeta, is the Garigliano river, which acts as border between the two compartments. Both rivers transport high volumes of organic and inorganic pollutants. The razor clams are harvested within the $0.3 \mathrm{~nm}$ (and mainly as close as possible to the coast line) because depth at greater distances suddenly increases and the granulometry deviates toward muddy sediments preventing the animals to sink.

In the two above-mentioned compartments about 17 dredgers are compressively active ( 3 operating in the Gaeta compartment and 14 in the Naples compartment), mainly fishing the razor clams (E. minor), but opportunistically also the striped venus clam (C. gallina; in the compartment of Naples only). In both compartments, the Catch per Unit Effort (CPUE; calculated as $\mathrm{kg}$ per hour per boat) oscillated between 6 and $14 \mathrm{~kg} \mathrm{~h}^{-1}$ in 2017 and between 6 and $16 \mathrm{~kg} \mathrm{~h}^{-1}$ in 2018 (with a maximum peak of $24 \mathrm{~kg} \mathrm{~h}^{-1}$ recorded in June in Gaeta; data obtained directly from logbooks compiled by fishers on behalf of the Italian Ministry for Agriculture and Fisheries for a scientific survey to request a derogation to the European Regulation 1967/2006 avoiding fishing with dredge within $0.3 \mathrm{~nm}$ ).

\section{Sampling Procedures}

To assess the impact of dredges on benthic communities, two surveys were carried out with commercial fishing vessels made available by the local consortia for bivalve molluscs' fishery management. In each survey, two different areas, named as impact (I) and control (C), were sampled. The I area was placed inside the main fishing grounds of the two compartments, while the $\mathrm{C}$ area was placed in the non-fishing area inside the compartment of Gaeta (Figure 1). In both $\mathrm{C}$ and I, transects were perpendicular to the coast, between 1.5 and $4 \mathrm{~m}$ depth and spaced 1.5-2 $\mathrm{nm}$ apart from each other. For each transect two to three random hauls were made (considered as replicates). Each haul, having a length of about $100 \mathrm{~m}$, was carried out parallel to the coast to keep the fishing depth as constant as possible and spaced between 30 and $150 \mathrm{~m}$ one to each other. In case 
of impediments at sea (e.g., breakwater barriers or ports) some transects or replicates have undergone a shift, or even deleted, compared to what was at the beginning planned. The first survey was done in winter 2017 (between November and December), for a total of 62 hauls (48 in I and 14 in C), while the second one was done between May and June 2018, for a total of 57 hauls (40 in $\mathrm{I}$ and 17 in $\mathrm{C}$ ). Between the two periods, fishing was closed during April and May 2018, following the Italian Regulation. Moreover, as fishers are obliged to monthly compile logbooks about the razor clam catches, from their data emerged that very few boats were active during the interval between the two surveys (mainly due to bad weather conditions). Thus, the time-lapse between the two surveys could be considered as a recovery time for the macro-benthos communities. The boats were equipped with dredges of $3 \mathrm{~m}$ width (respecting the limits of the European Regulation 1967/2006), with a metal rods distance adapt to collect the razor clam and no $<7 \mathrm{~mm}$ on the inferior side of the cage. The dredge was towed with the recovery of the anchor cable about $100 \mathrm{~m}$ long.

Since the dredge is not a well-suited gear to sample macrobenthos, a net sampler with fine meshes $(14 \mathrm{~mm})$ and dimensions $40 \mathrm{~cm}$ (width) per $20 \mathrm{~cm}$ (height) (Figure 2) was attached inside the dredge in order to sample the smallest specimens of razor clam and other macro-organisms.

The total weight of the net sampler capture was recorded. Subsequently, the catch was sub-sampled and stored at $-20^{\circ} \mathrm{C}$ to be sorted and analyzed in the laboratory. The macro-benthos sorting consisted in classifying organisms up to the lowest

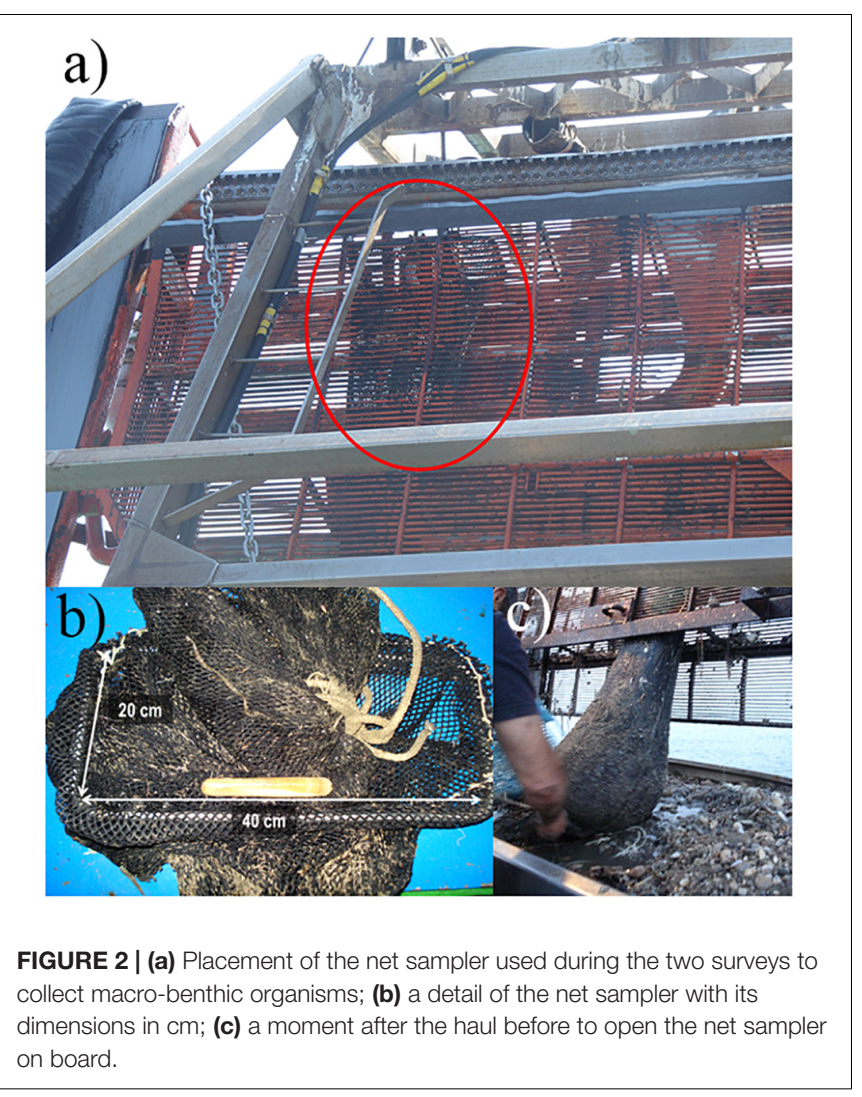

possible taxonomic level, counting the individuals and weighing each species or taxon present (precision $0.1 \mathrm{~g}$ ). All figures are reported as individual densities in $100 \mathrm{~m}^{2}$ of swept area.

\section{Data Analysis}

Prior the analysis, the fauna matrices of densities were simplified by excluding all those species that did not reach the $5 \%$ of presence of the total replicates. All data were then forthroot transformed to balance the contribution of very abundant species and maintain intact information on relative abundances (Legendre and Legendre, 2012). The E. minor individuals were not considered for the analysis, as it represents the target species.

Biodiversity indices were calculated both for the entire fauna communities and for the molluscs assemblages. ShannonWeiner's $H^{\prime}$ (based on $\log _{2}$ ) and Pielou's $J^{\prime}$ evenness values were calculated. One way analysis of variance (ANOVA) was used to assess differences between treatments (I vs. C) for the first period (the entire macrofauna community). Two-way ANOVA was used for the bivalve molluscs assemblages based on the factors treatment (I vs. C) and period (first survey and second survey). In case of significant differences, Tukey's honestly significant difference (HSD) test was adopted as a post hoc pairwise analysis to evaluate the pairs among the levels of the significant factors leading to the differences between treatments and years.

To assess the response of the entire communities to the dredges impact, a permutational multivariate analysis of variance (PERMANOVA; Anderson, 2001) was performed using the macro-fauna on the whole in the first survey and treatment as fixed factor. PERMANOVA was subsequently performed also using the factors treatment and period to assess the response of bivalve molluscs assemblages before and after fishing closure. Treatment and period were both considered as fixed factors. The similarities percentages (SIMPER) procedure was used to identify those species that contributed most to the dissimilarity between I and C.

The unconstrained ordination principal coordinate analysis (PCO) based on Bray-Curtis similarity was used to visualize data regarding the entire fauna communities. Subsequently the constrained ordination of the specific a priori hypotheses of interest, concerning differences among treatments over the two periods, was analyzed by means of canonical analysis of principal (CAP) components (Anderson and Willis, 2003). The

TABLE 1 | One-way ANOVA results of the two diversity indices $H^{\prime}$ (Shannon-Weiner diversity index) and $J^{\prime}$ (Pielou's evenness) of the two communities, and PERMANOVA result based on the Bray-Curtis similarity matrix of the two communities present in the two treatments (Impact and Control).

\begin{tabular}{llcrrrrr}
\hline ANOVA & Factor & df & SS & MS & $\boldsymbol{F}$ & $\boldsymbol{p}$ & \\
\hline$H^{\prime}$ & Treatment & 1 & 0.376 & 0.376 & 0.518 & 0.475 & \\
& Residuals & 60 & 43.583 & 0.726 & & & \\
& Treatment & 1 & 0.053 & 0.053 & 0.976 & 0.327 & \\
& Residuals & 60 & 3.235 & 0.054 & & & \\
\hline PERMANOVA & Factor & df & SS & MS & Pseudo- $\boldsymbol{F}$ & $\boldsymbol{p}$ & \multirow{2}{*}{ Perms } \\
\hline Macro-benthos & Treatment & 1 & 18,631 & 18,631 & 10.563 & 0.0001 & \multirow{2}{*}{9938} \\
community & Residuals & 60 & 105,830 & 1763.8 & & &
\end{tabular}


hypotheses were tested by obtaining a $p$-value using permutation procedures (9999 permutations) on the canonical test statistics (squared correlations, $\delta_{1}^{2}$ ) generated by the analysis. In both the ordinations, the relative contributions of each species to the differences found were assessed using the Pearson's correlation coefficient (cut-off 0.5).

All data analysis were performed with PRIMER v.6 with add on PERMANOVA+ (Anderson et al., 2008; Clarke et al., 2014) and the free statistical software R (R Core Team, 2018).

\section{RESULTS}

\section{Macro-Benthos}

Overall, 54 taxa were found (the complete lists are reported as Supplementary Tables), 51 of which classified to the species level: 32 molluscs, 12 crustaceans, 6 echinoderms, and 1 sipunculid. The other ones were not classified and left as

TABLE 2 | Simper table of the species that most differentiated the two treatment communities: Impact (I) and Control (C).

\begin{tabular}{|c|c|c|c|c|c|c|}
\hline \multicolumn{7}{|c|}{ Average dissimilarity between $I$ and $C=72.0$} \\
\hline Species & $\begin{array}{c}\text { Group I } \\
\text { Av.Abund }\end{array}$ & $\begin{array}{l}\text { Group C } \\
\text { Av.Abund }\end{array}$ & Av.Diss & Diss/SD & $\begin{array}{c}\text { Contrib } \\
\%\end{array}$ & $\underset{\%}{\text { Cum. }}$ \\
\hline Ec & 0.8 & 3.2 & 6.4 & 1.6 & 8.9 & 8.9 \\
\hline Dt & 3.1 & 1.7 & 5.7 & 1.3 & 7.9 & 16.7 \\
\hline $\mathrm{Cg}$ & 2.0 & 0.7 & 4.2 & 1.5 & 5.9 & 22.6 \\
\hline Oo & 0.9 & 2.1 & 4.2 & 1.3 & 5.8 & 28.4 \\
\hline $\mathrm{Te}$ & 1.6 & 0.0 & 4.2 & 0.8 & 5.8 & 34.2 \\
\hline$D p$ & 1.9 & 0.8 & 3.8 & 1.3 & 5.3 & 39.5 \\
\hline $\mathrm{Sm}$ & 1.5 & 0.0 & 3.6 & 1.3 & 4.9 & 44.4 \\
\hline Ms & 1.6 & 0.3 & 3.4 & 1.2 & 4.7 & 49.1 \\
\hline LV & 1.5 & 0.3 & 3.3 & 1.3 & 4.6 & 53.7 \\
\hline Polychaeta & 2.1 & 2.1 & 3.0 & 1.1 & 4.1 & 57.8 \\
\hline DI & 0.8 & 0.7 & 2.2 & 1.0 & 3.1 & 60.9 \\
\hline Ds & 1.0 & 0.2 & 2.2 & 0.5 & 3.0 & 63.9 \\
\hline Sn & 0.6 & 0.7 & 2.1 & 0.9 & 2.9 & 66.8 \\
\hline Cc & 0.9 & 0.0 & 2.0 & 0.9 & 2.8 & 69.6 \\
\hline $\mathrm{Nj}$ & 0.8 & 0.4 & 2.0 & 0.9 & 2.8 & 72.3 \\
\hline Pla & 0.5 & 0.4 & 1.8 & 0.8 & 2.4 & 74.8 \\
\hline $\mathrm{PI}$ & 0.8 & 0.0 & 1.7 & 0.7 & 2.3 & 77.1 \\
\hline At & 0.3 & 0.5 & 1.5 & 0.7 & 2.1 & 79.1 \\
\hline $\mathrm{Tt}$ & 0.6 & 0.0 & 1.3 & 0.4 & 1.9 & 81.0 \\
\hline $\mathrm{Pe}$ & 0.5 & 0.3 & 1.3 & 0.7 & 1.8 & 82.8 \\
\hline $\mathrm{Mc}$ & 0.5 & 0.0 & 1.2 & 0.5 & 1.7 & 84.5 \\
\hline $\mathrm{Nm}$ & 0.3 & 0.3 & 1.1 & 0.6 & 1.5 & 86.0 \\
\hline $\mathrm{Ta}$ & 0.5 & 0.0 & 1.0 & 0.5 & 1.4 & 87.4 \\
\hline $\mathrm{Ca}$ & 0.2 & 0.3 & 1.0 & 0.5 & 1.4 & 88.8 \\
\hline $\mathrm{Gg}$ & 0.0 & 0.4 & 1.0 & 0.5 & 1.3 & 90.1 \\
\hline
\end{tabular}

Cumulative cut-off at 90\%. Ec, Echinocardium cordatum; Dt, Donax trunculus; Cg. Chamelea gallina; Oo, Ophiura ophiura; Te, Tellina exigua; Dp. Diogenes pugilator; Sm, Solen marginatus; Ms, Mactra stultorum; Lv, Liocarcinus vernalis; Polychaeta, whole unclassified polychaete individuals; DI, Dosinia lupinus; Ds, Donax semistriatus; Sn, Sipunculus nudus; Cc, Callianassa candida; Nj, Neverita josephinia; Pla, Portunus latipes; Pl, Pharus legumen; At, Acanthocardia tuberculata; Tt, Tellina tenuis; Pe, Platysquilla eusebia; Mc, Macoma cumana; Nm, Nassarius mutabilis; Ta, Tellina albicans; Ca, Carcinus aestuarii; Gg, Glycymeris glycymeris. generic taxa: cnidarian, nemertean, and polychaeta. As evident, molluscs dominated both in terms of species and in term of individual densities.

The diversity indices (see Supplementary Tables for a detail summary of the indices for each replicate) calculated basing on the entire community of the first survey did not show any differences between I and $\mathrm{C}$ (Table 1). On average, $H^{\prime}$ values were $1.8 \pm 0.8$ (mean \pm standard deviation) and $2.0 \pm 0.9$ for $\mathrm{C}$ and $\mathrm{I}$, respectively. Regarding $J^{\prime}$ values they were on average $0.6 \pm 0.3$ and $0.6 \pm 0.2$ for $C$ and I, respectively.

Seventeen species did not reach the cut-off of the $5 \%$ of presence overall the samples. The multivariate analysis on the rest of the community showed a difference between the individual densities in I and C, as reported by the PERMANOVA (Table 1). SIMPER results showed an average dissimilarity between $\mathrm{C}$ and I of $72 \%$ and the species that most contributed to this dissimilarity are reported in Table 2.

The PCO clearly represented these differences with a good separation between $\mathrm{I}$ and $\mathrm{C}$ in the bi-dimensional space, with the first axis of PCO explaining $22 \%$ and the second axis $19.5 \%$ of the total variance (the first four axes alone explained $>60 \%$ of the total variance; Figure 3 ). The species that were mainly correlated (Pearson's correlation $>0.5$ ) with the first two axes and that mostly contributed to the plot configuration are: Donax trunculus, Tellina exigua, Solen marginatus, C. gallina, Liocarcinus vernalis, Mactra stultorum, and Donax semistriatus more associated to the I hauls, while Ophiura ophiura and Echinocardium cordatum were more related to the $\mathrm{C}$ hauls. The

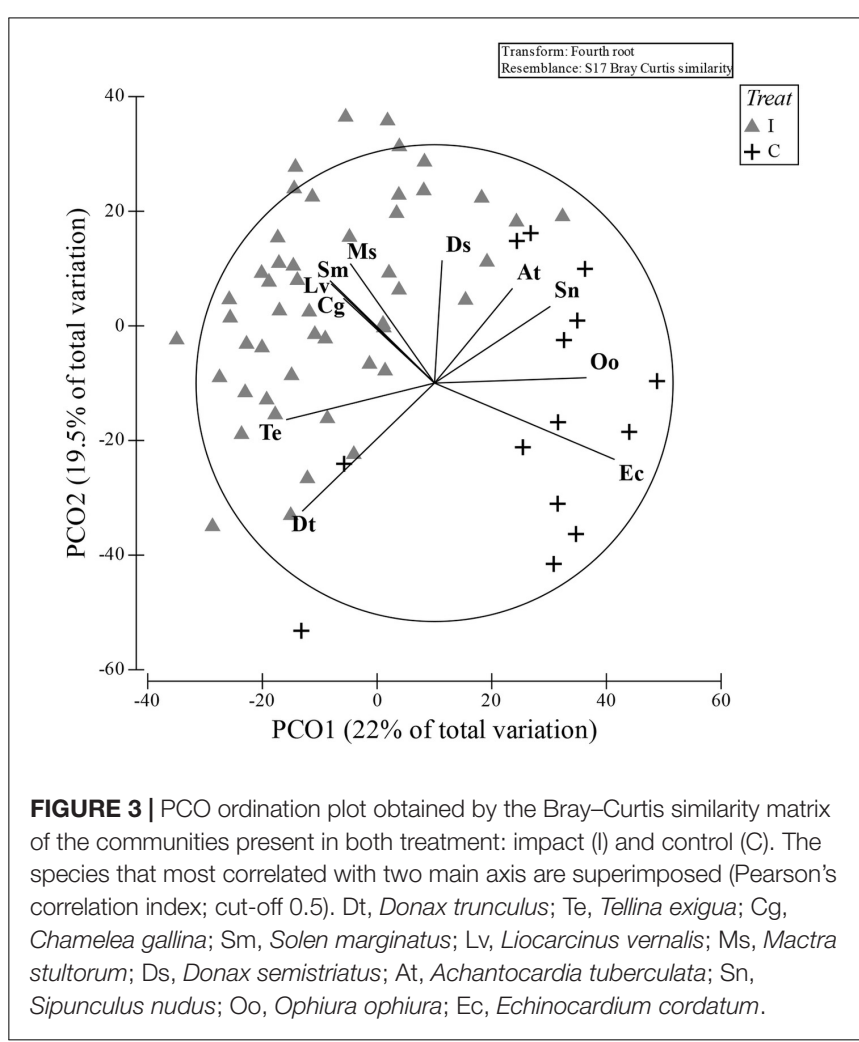


TABLE 3 | One-way ANOVA results of the two diversity indices $H^{\prime}$ (Shannon-Weiner diversity index) and $J^{\prime}$ (Pielou's evenness) of the molluscs assemblages, and PERMANOVA result for the molluscs assemblages based on the Bray-Curtis similarity matrix of the two communities present in the two treatments (Impact and Control) and in the two periods (2017 and 2018).

\begin{tabular}{|c|c|c|c|c|c|c|c|}
\hline ANOVA & Factor & df & ss & MS & $\boldsymbol{F}$ & $p$ & \\
\hline \multirow[t]{4}{*}{$H^{\prime}$} & Period & 1 & 6.203 & 6.203 & 12.033 & 0.001 & \\
\hline & Treatment & 1 & 4.309 & 4.309 & 8.359 & 0.005 & \\
\hline & Period $\times$ Treatment & 1 & 0.163 & 0.163 & 0.316 & 0.575 & \\
\hline & Residuals & 113 & 58.765 & 0.516 & & & \\
\hline \multirow[t]{4}{*}{$J^{\prime}$} & Period & 1 & 0.689 & 0.689 & 7.284 & 0.008 & \\
\hline & Treatment & 1 & 0.020 & 0.020 & 0.215 & 0.644 & \\
\hline & Period $\times$ Treatment & 1 & 0.015 & 0.015 & 0.155 & 0.695 & \\
\hline & Residuals & 113 & 10.779 & 0.095 & & & \\
\hline PERMANOVA & Factor & df & SS & MS & Pseudo-F & $p$ & Perms \\
\hline \multirow[t]{4}{*}{ Bivalves molluscs assemblages } & Period & 1 & 7791 & 7791 & 3.876 & 0.004 & 9949 \\
\hline & Treatment & 1 & 22,723 & 22,723 & 11.305 & 0.000 & 9943 \\
\hline & Period $\times$ Treatment & 1 & 3561 & 3561 & 1.772 & 0.112 & 9955 \\
\hline & Residuals & 113 & 229,140 & 2010 & & & \\
\hline
\end{tabular}
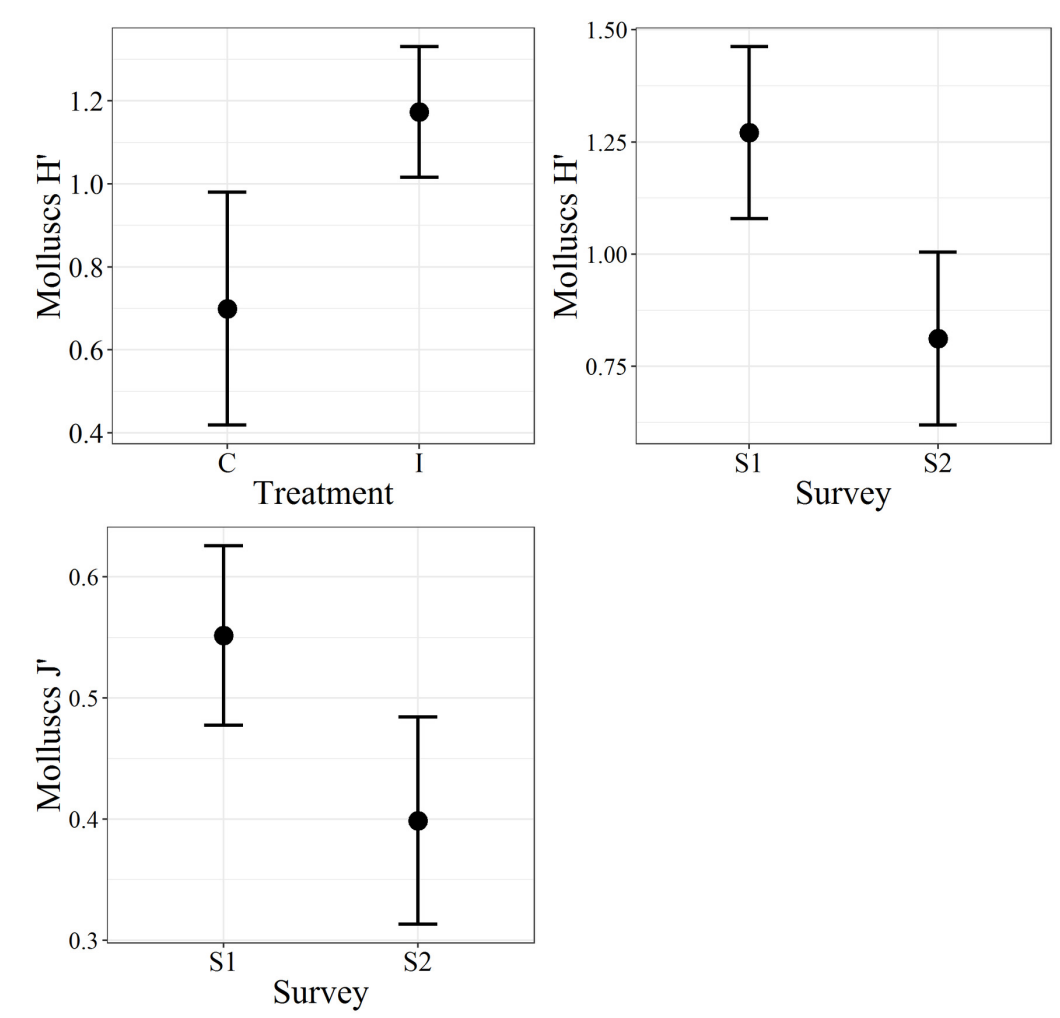

FIGURE 4 | The Plot of the molluscs biodiversity indices. $H^{\prime}$, Shannon-Wiener diversity index; J', Pielou's evenness; C, control; I, impact; S1, first survey; S2, second survey. The bars represent the 95\% confidence intervals.

two species Acanthocardia tubercolata and Sipunculus nudus were almost borderline in discriminating between the two treatments.

\section{Bivalves Molluscs}

In the first survey, 26 species of bivalve molluscs were collected against 13 species found in the second survey. This decrease was significant, as reported by the ANOVA (Table 3) applied to the diversity indices (see Supplementary Material for a detailed summary of the indices for each replicate). The interaction term of the ANOVA was not significant meaning that, according to the results of the benthic communities, the molluscs assemblages did not show differences in the diversity indices between I and $\mathrm{C}$ in both surveys. Notwithstanding, differences were observed between the two surveys both for $H^{\prime}$ and $J^{\prime}$ and between treatments only for $H^{\prime}$ (Figure 4). Average values of $1.27 \pm 0.75$ and $0.81 \pm 0.72$ were observed for $H^{\prime}$ in 2017 and 2018, 
respectively, while for $J^{\prime} 0.55 \pm 0.29$ and $0.40 \pm 0.32$ in 2017 and 2018, respectively. Concerning the treatments, average values of $0.70 \pm 0.75$ and $1.17 \pm 0.74$ were observed for $H^{\prime}$ for $\mathrm{C}$ and $\mathrm{I}$, respectively. Prior the multivariate analysis, 10 species were discarded because they did not reach the $5 \%$ cut-off overall the samples. The PERMANOVA did not highlight any differences in the interaction term, confirming the ANOVA results (Table 3). On the other hand, both the two surveys and treatments overall showed significant differences. The SIMPER (Table 4) results showed an average dissimilarity between survey 1 and survey 2 of $66.1 \%$, while the dissimilarity between I and C was $70.9 \%$.

The plot resulting by the CAP analysis (Figure 5) was coherent with the results obtained by the PERMANOVA, showing a clear separation between I and C in both surveys. The total correct allocation of the points in the plot resulted as $67.8 \%$, thus with a misclassification error of $32.2 \%$. The confusion matrix (Table 5) produced by the CAP analysis showed high allocation success percentages of sites inside treatments and surveys. The species that in the plot discriminated most the treatments were

TABLE 4 | Simper table of the molluscs species that most differentiated the two periods (2017 and 2018) and the two treatments: Impact (I) and Control (C).

\begin{tabular}{lcccccc}
\hline \multicolumn{7}{l}{ Average dissimilarity between S1 and S2 $\mathbf{6 6 . 1}$} \\
\hline Species & $\begin{array}{c}\text { Group S1 } \\
\text { Av.Abund }\end{array}$ & $\begin{array}{c}\text { Group S2 } \\
\text { Av.Abund }\end{array}$ & Av.Diss & Diss/SD & $\begin{array}{c}\text { Contrib } \\
\%\end{array}$ & $\begin{array}{c}\text { Cum. } \\
\%\end{array}$ \\
\hline $\mathrm{Dt}$ & 2.8 & 2.8 & 12.4 & 1.1 & 18.8 & 18.8 \\
$\mathrm{Cg}$ & 1.7 & 1.0 & 7.7 & 1.2 & 11.6 & 30.4 \\
$\mathrm{Ds}$ & 0.8 & 1.0 & 6.6 & 0.8 & 10.0 & 40.4 \\
$\mathrm{Ms}$ & 1.3 & 0.8 & 6.2 & 1.1 & 9.4 & 49.8 \\
$\mathrm{Sm}$ & 1.2 & 0.8 & 6.1 & 1.1 & 9.2 & 58.9 \\
$\mathrm{Te}$ & 1.3 & 0.0 & 5.7 & 0.7 & 8.6 & 67.5 \\
$\mathrm{Dl}$ & 0.8 & 0.3 & 4.3 & 0.8 & 6.5 & 74.1 \\
$\mathrm{Ta}$ & 0.4 & 0.4 & 2.9 & 0.6 & 4.4 & 78.5 \\
$\mathrm{At}$ & 0.4 & 0.3 & 2.9 & 0.5 & 4.3 & 82.8 \\
$\mathrm{Tp}$ & 0.2 & 0.5 & 2.8 & 0.6 & 4.3 & 87.1 \\
$\mathrm{Pl}$ & 0.6 & 0.1 & 2.8 & 0.6 & 4.3 & 91.4 \\
\hline
\end{tabular}

Average dissimilarity between $I$ and $C=70.9$

\begin{tabular}{lcccccc}
\hline Species & $\begin{array}{c}\text { Group I } \\
\text { Av.Abund }\end{array}$ & $\begin{array}{c}\text { Group C } \\
\text { Av.Abund }\end{array}$ & Av.Diss & Diss/SD & $\begin{array}{c}\text { Contrib } \\
\%\end{array}$ & $\begin{array}{c}\text { Cum. } \\
\%\end{array}$ \\
\hline $\mathrm{Dt}$ & 3.0 & 2.1 & 14.2 & 1.2 & 20.1 & 20.1 \\
$\mathrm{Cg}$ & 1.6 & 0.7 & 8.9 & 1.3 & 12.6 & 32.7 \\
$\mathrm{Sm}$ & 1.3 & 0.0 & 7.8 & 1.1 & 11.0 & 43.7 \\
$\mathrm{Ms}$ & 1.3 & 0.3 & 7.2 & 1.2 & 10.1 & 53.8 \\
$\mathrm{Ds}$ & 1.0 & 0.5 & 7.0 & 0.7 & 9.8 & 63.6 \\
$\mathrm{Te}$ & 0.9 & 0.0 & 4.7 & 0.5 & 6.6 & 70.2 \\
$\mathrm{Dl}$ & 0.6 & 0.5 & 4.6 & 0.8 & 6.5 & 76.6 \\
$\mathrm{At}$ & 0.4 & 0.2 & 3.0 & 0.5 & 4.3 & 80.9 \\
$\mathrm{Tp}$ & 0.4 & 0.2 & 3.0 & 0.6 & 4.2 & 85.1 \\
$\mathrm{Ta}$ & 0.5 & 0.0 & 2.9 & 0.5 & 4.0 & 89.1 \\
$\mathrm{Pl}$ & 0.5 & 0.0 & 2.5 & 0.5 & 3.6 & 92.7 \\
\hline
\end{tabular}

Cumulative cut-off at 90\%. At, Acanthocardia tuberculata; Cg, Chamelea gallina; Ds, Donax semistriatus; Dt, Donax trunculus; Dl, Dosinia lupinus; Ms, Mactra stultorum; PI, Pharus legumen; Ta, Tellina albicans; Te, Tellina exigua; Tp, Tellina planata; Sm, Solen marginatus.
S. marginatus, M. stultorum, C. gallina, T. exigua, Pharus legumen (mainly associated to the horizontal axis and positively related to the I treatment), and Dosinia lupinus (mainly related to the vertical axis and I treatment).

\section{DISCUSSION}

The impact of fishing activities on shallow benthic communities is hard to detect. Among the difficulties, it is important to stress that there are no well-defined reference data for which comparisons between fished and unfished habitats can be made. Highly dynamic environments, such as those where the razor clam lives in, mask potential community changes caused by fishing gears. Therefore, it can be difficult to separate the effect of fishing effort from natural variability in dynamic shelf-sea systems (Szostek et al., 2015). Moreover, most of the benthic species have multiple life cycle stages that can be influenced by extrinsic disturbance factors that could be considered of more importance (e.g., factors controlling recruitment and settlement; Morello et al., 2005). Thus, the effects of fishing will not depend only on fishing pressure over time, but also on the life history traits of the species within the communities, on interspecific interactions and on the interactions between them and the environment (Thrush and Dayton, 2002). The unpredictability of natural disturbance events of great importance in shallow waters (such as storms) further decrease the discernment between natural and fishing induced impact. Therefore, it is plausible that the assemblages in a fishing ground are already tolerant to physical disturbance (Morello et al., 2006; Szostek et al., 2015).

The results reported here clearly show a distinction of the macro-benthic communities between impact and control sites, although the diversity indices did not show any differences between them. The two treatments were characterized by different species, although molluscs represented the predominant taxon. In both treatments, the main species were opportunistic. At $\mathrm{C}$ sites the most abundant species were E. cordatum and O. ophiura, two echinoderms considered as mobile opportunistic scavengers, and this lets hypothesize that the razor clam shallow waters habitat is characterized by communities of well-adapted species to environmental disturbance. Echinocardium cordatum is reported as the most vulnerable species with respect to bottom fishing (Tuck et al., 2000). This fragile echinoderm buries sufficiently deeply into the sediment, between 2 and $20 \mathrm{~cm}$ (Tortonese, 1965), but razor clams dredges are able to penetrate even to $15 \mathrm{~cm}$ deep or more, thus the catchability of the species is high. Therefore, the fact that both E. cordatum and O. ophiura drastically decrease in number is probably due to their fragility, having both fragile exoskeletons. In I areas, the two echinoderms are clearly substituted by molluscs (D. trunculus, C. gallina, T. exigua, S. marginatus, M. stultorum) and crustaceans (D. pugilator and L. vernalis) that, due to their hard shells, better resist to fishing stresses and mechanical damages. The hermit crab $D$. pugilator is considered as highly correlated with "moderate fishing intensity" (Morello et al., 2006). The moderate fishing activity is consistent with the fishing effort of the study area, because the number of vessels operating is quite low with 


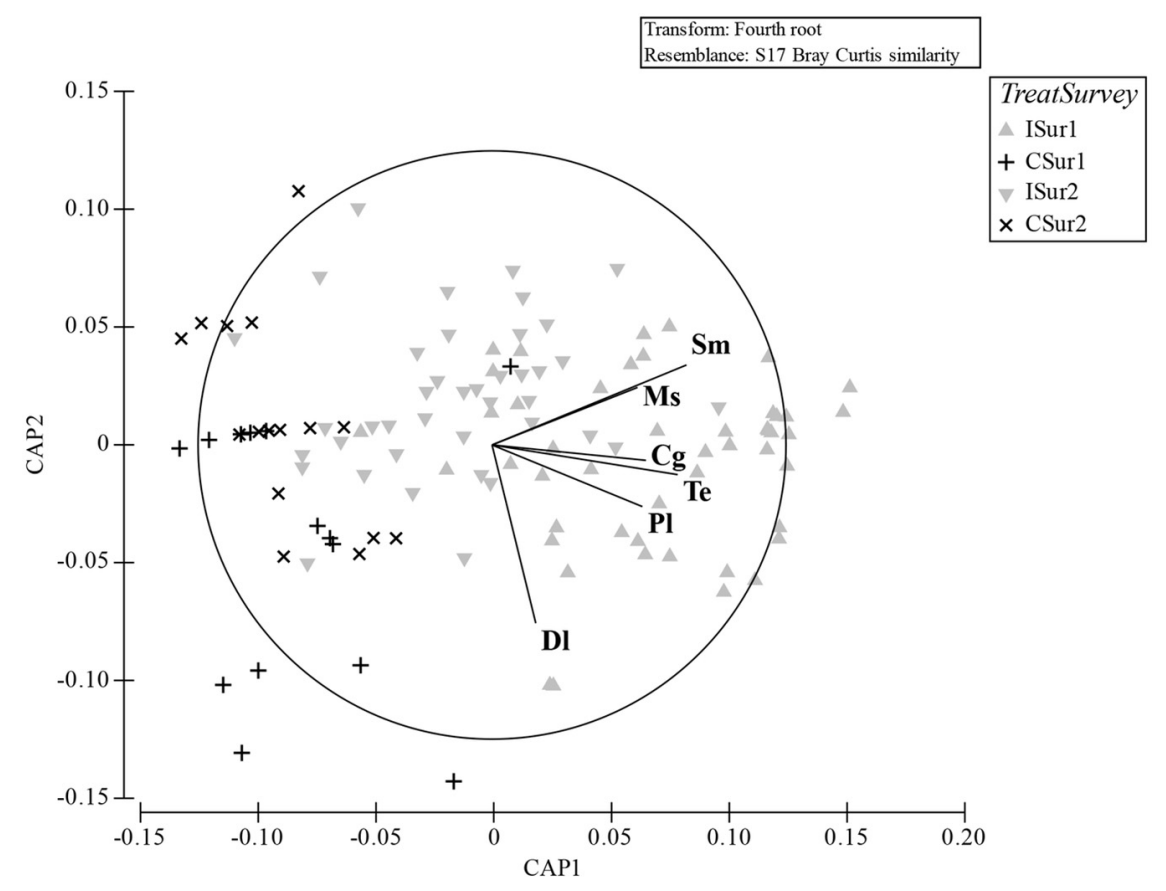

FIGURE 5 | CAP analysis ordination plot based on the Bray-Curtis similarity matrix of the molluscs assemblages sampled during the two surveys with superimposed the species that most differentiated the replicates (Pearson's correlation index; cut-off 0.5). I, impact; C, control; Sur1, first survey; Sur2, second survey. DI, Dosinia lupinus; Sm, Solen marginatus; Ms, Mactra stultorum; Cg, Chamelea gallina; PI, Pharus legumen; Te, Tellina exigua.

respect to the entire available fishing ground. Moreover, very often a few boats are active over the year and with an average of days at sea of 24 days/boat/year, thus further reducing the effective effort. Diogenes pugilator is not particularly vulnerable to hydraulic dredging because the protection of the gastropod shell prevents any injury. Species like the hermit crab may even benefit from the hydraulic dredging as observed by Hauton et al. (2003) which observed numerous individuals aggregating to feed on dredge discards. The sorting of razor clams of legal size is made on board by hand, thus hard shell molluscs are not damaged by the operation as it could be, e.g., for the striped venus clams that are sorted mechanically (Moschino et al., 2003). For example, Morello et al. (2006) reported a $60 \%$ of damage for M. stultorum individuals because of the sieving operations carried out to sort the catch, and crushed individuals did not survive after the return at sea.

The great presence of filter and suspension feeder bivalve molluscs in the I samples is potentially linked to the suspension of sediment produced by the regular and constant trawling of the dredges. In fact, when fishers localize a patch of Ensis, they cross the area number of times (as also evident by the logbooks obtained by fishers; data not shown), which may results in profound effects (Tuck et al., 2000; Reiss et al., 2009). In fact, one of the main issue of dredges is the sediment resuspension and subsequent the macronutrient contained in it (Tuck et al., 2000; Kaiser et al., 2002; Lucchetti and Sala, 2012), that would favor the filter and suspension feeding strategy of well-adapted animals. It is then noteworthy even the presence of polychaetes in both I and C sites. Polychaetes are known to be a taxon typically occurring in disturbed sediments and their presence in both I and $\mathrm{C}$ confirms the fact that both treatments are effectively two disturbed environments with mix effects of natural and anthropic impacts regarding the I and only natural impact regarding $\mathrm{C}$.

In the second survey the diversity (at least for molluscs) was not an issue between I and C. As a confirmation that a reduced suspension of sediment due to a substantial reduction of dredging activity, in the time-lapse between the two surveys the number of filter feeders decreased. The reduction in species richness in non-impacted areas respect to the impacted ones is not so unexpected. Vasapollo (2010) found a net difference in the polychaete assemblages in two different Posidonia oceanica seagrass meadows: the highest diversity was found in a heavily impacted meadow due to a migration of species from bared soft sediments.

TABLE 5 | Confusion matrix derived by the CAP analysis based on the Bray-Curtis similarity matrix of the molluscs assemblages, and indicating the percentage of correct placement of each replicate of the two surveys. I: Impact; C: Control.

\begin{tabular}{lcccccc}
\hline Original group & $\mathbf{I 2 0 1 7}$ & $\mathbf{C 2 0 1 7}$ & $\mathbf{I 2 0 1 8}$ & $\mathbf{C 2 0 1 8}$ & Total & \% Correct \\
\hline I2017 & 38 & 1 & 8 & 1 & 48 & 79.2 \\
C2017 & 0 & 8 & 1 & 5 & 14 & 57.1 \\
I2018 & 4 & 4 & 24 & 8 & 40 & 60.0 \\
C2018 & 0 & 5 & 1 & 10 & 16 & 62.5 \\
Total & 42 & 18 & 34 & 24 & 118 & \\
\hline
\end{tabular}

Total correct: 80/118 (67.8\%)

$\delta_{1}^{2}=0.678 ; p=0.0001$ 
In the light of the present observations, it is interesting to report the consequences that a diminished number of filter and suspension feeders may have on the target species E. minor. It has been observed that at the end of the period of fishing closure, right after May, the number of razor clams fished is extremely high. The reduction of filter feeders may have the effect to allow a high survival rate for the razor clam eggs and larvae, which potentially may grow up to commercial sizes. Therefore, as a paradox, this might happen not because of a biodiversity recovery to pristine conditions but because of a decrease of larvae and razor clam eggs potential predator. Thus, from a management point of view, a longer fishing closure could favor a bigger catch of clams in comparison with the actual 2 months of closure, and consequently this might translate in a better conservation of the species if catches were well managed. The new Italian Management Plan for hydraulic dredges proposed in the last months (DGPEMAC, 2019) that also includes the razor clam fishing management goes in this direction. In the new management plan, it has been proposed a fishing closure of 6 months during the razor clam gonads maturation and larvae development, and a minor daily quota per boat (namely, $100 \mathrm{~kg}$ per boat per day). In light of the results obtained, this period could represents a good choice. This is also supported by Thrush and Dayton (2002) and Morello et al. (2006) which highlighted that marine benthic communities in dredged areas suffer from the effects produced by fishing activities for at least 3 months.

\section{CONCLUSION}

In conclusion, it is noteworthy that the recovery of benthic communities is important in the view of an ecosystem-based fisheries management. However, it is difficult to implement in practice. The problem relates to the definition of "recovery," since so far, there are no standard recovery reference points for populations or communities (Gilkinson et al., 2005). Presently, our ability to address the functional consequences associated to fishing impact is limited given the complexity of ecosystems, and our limited knowledge of component species and their interactions. Consequently, the prediction of the effects of removing or damaging a large number of benthic animals and species is still almost difficult. Moreover, care must be taken when "standard" monitoring programs carry on with the objective of the mere analysis of the biodiversity based on the diversity indices. As evident, an impact could be masked by substitution

\section{REFERENCES}

Amos, C. L., Umgiesser, G., Tosi, L., and Townend, I. H. (2010). The coastal morphodynamics of Venice lagoon, Italy: an introduction. Cont. Shelf Res. 30, 837-846. doi: 10.1016/j.csr.2010.01.014

Anderson, M. (2001). A new method for non-parametric multivariate analysis of variance. Austral. Ecol. 26, 32-46. doi: 10.1111/j.1442-9993.2001.01070.pp.x

Anderson, M., Gorley, R., and Clarke, K. (2008). PERMANOVA + for PRIMER: Guide to Software and Statistical Methods. Plymouth: PRIMER-e.

Anderson, M., and Willis, T. (2003). Canonical analysis of principal coordinates: a useful method of constrained ordination for ecology. Ecology 84, 511-525. doi: 10.1890/0012-9658(2003)084\%5B0511:caopca\%5D2.0.co;2 of species more tolerant to impacts or conversely, species might be attracted by the impact itself increasing the biodiversity respect to "pristine" areas. Paradoxically, as a consequence, even a small decrease in biodiversity might favor the recovery of fishing target species such as the razor clams that can take advantages by the low densities of their eggs and larvae potential predators that have expanded their habitat ranges due to the impact causes. Finally, to really understand what happens to the benthic communities when an area is closed to fishery, experimental closure studies is recommended to confirm the observations that emerged by the present study.

\section{DATA AVAILABILITY STATEMENT}

All datasets generated for this study are included in the article/Supplementary Material.

\section{AUTHOR CONTRIBUTIONS}

$\mathrm{CV}$ made the analysis and wrote the manuscript. $\mathrm{CV}, \mathrm{MV}, \mathrm{RD}$, $\mathrm{GB}$, and AP made the data collection. MV, RD, GB, AP, EP, and $\mathrm{AL}$ reviewed the manuscript.

\section{FUNDING}

The research was made on the European Data Collection Framework and financially supported by the Italian Ministry for Agricultural, Food and Forestry Policies (MiPAAF).

\section{ACKNOWLEDGMENTS}

The authors are indebted with the crews of the vessels for their support and with all the students and personnel of the CNR IRBIM of Ancona that kindly helped with laboratory activities.

\section{SUPPLEMENTARY MATERIAL}

The Supplementary Material for this article can be found online at: https://www.frontiersin.org/articles/10.3389/fmars. 2020.00014/full\#supplementary-material

Clarke, K., Gorley, R., Somerfield, P., and Warwick, R. (2014). Change in Marine Communities: An Approach to Statistical Analysis and Interpretation, 3rd Edn. Plymouth: PRIMER-E.

DGPEMAC, (2019). Piano di Gestione Nazionale per le Attività di Pesca con il Sistema Draghe idrauliche e Rastrelli da Natante. Public Law No. 9913, 17/06/2019. Roma: Italian Ministry for Agricultural, Food and Forestry Policies.

Frid, C., Clark, R., and Hall, J. (1999). Long-term changes in the benthos on a heavily fished ground off the NE coast of England. Mar. Ecol. Prog. Ser. 188, 13-20. doi: 10.3354/meps188013

Gilkinson, K. D., Gordon, D. C., MacIsaac, K. G., McKeown, D. L., Kenchington, E. L. R., Bourbonnais, C., et al. (2005). Immediate impacts and recovery trajectories of macrofaunal communities following hydraulic clam dredging 
on Banquereau, eastern Canada. ICES J. Mar. Sci. 62, 925-947. doi: 10.1016/ j.icesjms.2005.03.009

Hauton, C., Atkinson, R. J. A., and Moore, P. G. (2003). The impact of hydraulic blade dredging on a benthic megafaunal community in the Clyde Sea area, Scotland. J. Sea Res. 50, 45-56. doi: 10.1016/s1385-1101(03)00 045-5

Kaiser, M. (1998). Significance of bottom-fishing disturbance. Conserv. Biol. 12, 1230-1235. doi: 10.1046/j.1523-1739.1998.0120061230.x

Kaiser, M., Ramsey, C., Richardson, C., Spence, F., and Brand, A. (2000). Chronic fishing disturbance has changed shelf sea benthic community structure. J. Anim. Ecol. 69, 494-503. doi: 10.1046/j.1365-2656.2000.00412.x

Kaiser, M. J., Collie, J. S., Hall, S. J., Jennings, S., and Poiner, I. R. (2002). Modification of marine habitats by trawling activities: prognosis and solutions. Fish Fish. 3, 114-136. doi: 10.1046/j.1467-2979.2002.00079.x

Legendre, P., and Legendre, L. (2012). Numerical Ecology. Amsterdam: Elsevier.

Lucchetti, A., and Sala, A. (2012). Impact and performance of Mediterranean fishing gear by side-scan sonar technology. Can. J. Fish. Aquat. Sci. 69, 18061816. doi: 10.1139/f2012-107

Morello, E. B., Froglia, C., Atkinson, R. J. A., and Moore, P. G. (2005). Impacts of hydraulic dredging on a macrobenthic community of the Adriatic Sea, Italy. Can. J. Fish. Aquat. Sci. 62, 2076-2087. doi: 10.1007/s00227-005-0195-y

Morello, E. B., Froglia, C., Atkinson, R. J. A., and Moore, P. G. (2006). Mediumterm impacts of hydraulic clam dredgers on a macrobenthic community of the Adriatic Sea (Italy). Mar. Biol. 149, 401-413. doi: 10.1007/s00227-0050195-y

Moschino, V., Deppieri, M., and Marin, M. G. (2003). Evaluation of shell damage to the clam Chamelea gallina captured by hydraulic dredging in the Northern Adriatic Sea. ICES J. Mar. Sci. 60, 393-401. doi: 10.1016/S1054

Palanques, A., Guillen, J., and Puig, P. (2001). Impact of bottom trawling on water turbidity and muddy sediment of an unfished continental shelf. Oceanography 46, 1100-1110. doi: 10.4319/lo.2001.46.5.1100

Petetta, A., Bargione, G., Vasapollo, C., Virgili, M., and Lucchetti, A. (2019). Length-weight relationships of bivalve species in Italian razor clam Ensis minor (Chenu, 1843) (Mollusca: Bivalvia) fishery. Eur. Zool. J. 86, 363-369. doi: 10. 1080/24750263.2019.1668066

R Core Team (2018). R: A Language and Environment for Statistical Computing. Vienna: R Foundation for Statistical Computing.

Reiss, H., Greenstreet, S. P. R., Sieben, K., Ehrich, S., Piet, G. J., Quirijns, F., et al. (2009). Effects of fishing disturbance on benthic communities and secondary production within an intensively fished area. Mar. Ecol. Prog. Ser. 394, 201-213. doi: $10.3354 /$ meps 08243
Snelgrove, P. (1999). Getting to the bottom of marine biodiversity: sedimentary habitats - ocean bottoms are the most widespread habitat on earth and support high biodiversity and key ecosystem services. Bioscience 49, 129-138.

Strozzi, T., Teatini, P., and Tosi, L. (2009). TerraSAR-X reveals the impact of the mobile barrier works on Venice coastland stability. Remote Sens. Environ. 113, 2682-2688. doi: 10.1016/j.rse.2009.08.001

Szostek, C. L., Murray, L. G., Bell, E., Rayner, G., and Kaiser, M. J. (2015). Natural vs. fishing disturbance: drivers of community composition on traditional king scallop, Pecten maximus, fishing grounds. ICES J. Mar. Sci. 73, 70-83. doi: 10.1093/icesjms/fsv152

Thrush, S. F., and Dayton, P. K. (2002). Disturbance to marine benthic habitats by trawling and dredging: implications for marine biodiversity. Annu. Rev. Ecol. Syst. 33, 449-473. doi: 10.1146/annurev.ecolsys.33.010802.150515

Tortonese, E. (1965). Fauna d'Italia: Echinodermata. Bologna: Calderini.

Tuck, I. D., Bailey, N., Harding, M., Sangster, G., Howell, T., Graham, N., et al. (2000). The impact of water jet dredging for razor clams, Ensis spp., in a shallow sandy subtidal environment. J. Sea Res. 43, 65-81. doi: 10.1016/S1385-1101(99) 00037-4

Urra, J., Garcia, T., Leon, E., Gallardo-Roldan, H., Lozano, M., Baro, J., et al. (2017). Discard analysis and damage assessment in the wedge clam mechanized dredging fisheries of the northern Alboran Sea (W Mediterranean Sea). Fish. Res. 187, 58-67. doi: 10.1016/j.fishres.2016.10.018

Vasapollo, C. (2010). Spatio-Temporal Variability of Plant Features and Motile Invertebrates in Posidonia Oceanica Seagrass Meadows. Ph D. thesis, The Open University, Milton Kyenes.

Watling, L., Findlay, R., Mayer, L., and Schick, D. (2001). Impact of a scallop drag on the sediment chemistry, microbiota, and faunal assemblages of a shallow subtidal marine benthic community. J. Sea Res. 46, 309-324. doi: 10.1016/ s1385-1101(01)00083-1

Conflict of Interest: The authors declare that the research was conducted in the absence of any commercial or financial relationships that could be construed as a potential conflict of interest.

Copyright (c) 2020 Vasapollo, Virgili, Bargione, Petetta, De Marco, Punzo and Lucchetti. This is an open-access article distributed under the terms of the Creative Commons Attribution License (CC BY). The use, distribution or reproduction in other forums is permitted, provided the original author(s) and the copyright owner(s) are credited and that the original publication in this journal is cited, in accordance with accepted academic practice. No use, distribution or reproduction is permitted which does not comply with these terms. 